Original Article

\title{
DEVELOPMENT AND VALIDATION OF UV SPECTROSCOPIC METHODS FOR SIMULTANEOUS ESTIMATION OF SALBUTAMOL SULPHATE AND DOXOPHYLLINE IN COMBINED SOLID DOSAGE FORM
}

\author{
ANJOO KAMBOJ*, PAWAN SIDANA, UPENDRA K JAIN \\ Chandigarh College of Pharmacy, Landran, Mohali (Punjab) \\ Email: anjookamboj@gmail.com
}

Received: 29 Aug 2016 Revised and Accepted: 29 Apr 2017

\section{ABSTRACT}

Objective: Salbutamol sulphate (SBS) and doxophylline (DOX) was used for the treatment of asthma and bronchitis. In the present study, two simple, accurate, precise, reproducible and economical UV-spectroscopic methods (A and B) for simultaneous estimation of SBS and DOX in tablet dosage form have been developed.

Methods: In the present study the simultaneous estimation of SBS and DOX was carried out by two methods. Method A employs solving of simultaneous equations based on the measurement of absorbance at two wavelengths, $272 \mathrm{~nm}$ and $276 \mathrm{~nm}$ which are the $\lambda_{\text {max }}$ values of SBS and DOX respectively in phosphate buffer ( $\mathrm{pH} 7.4$ ). Method B is based on the principle of $Q$-Analysis where in, absorbance was measured at $225 \mathrm{~nm}$ (iso-absorptive point, $\left.\lambda_{1}\right)$ and $276 \mathrm{~nm}\left(\lambda_{\max }\right.$ of DOX, $\left.\lambda_{2}\right)$ in phosphate buffer (pH 7.4).

Results: Both SBS and DOX shows linearity at all the selected wavelengths and obeys beer's law in the concentration range of between $0.2-1.6 \mu \mathrm{g} / \mathrm{ml}$ and $0.1-3.5 \mu \mathrm{g} / \mathrm{ml}$ at $276 \mathrm{~nm} ; 0.2-1.6 \mu \mathrm{g} / \mathrm{ml}$ and $0.1-4.5 \mu \mathrm{g} / \mathrm{ml}$ at $272 \mathrm{~nm}$ and $0.2-2.0 \mu \mathrm{g} / \mathrm{ml}$ and $0.2-3.5 \mu \mathrm{g} / \mathrm{ml}$ at iso-absorptive point $225 \mathrm{~nm}$. Recovery studies for SBS and DOX were performed and the percentage recovery for both the drugs was obtained in the range of $97.45-98.63 \%$ (Method A) and 97.49-98.87\% (Method B) confirming the accuracy of the proposed method.

Conclusion: Both the methods showed good reproducibility and recovery with \% RSD less than 2 . Statistical validation of the data shows that the proposed methods can be successfully applied for the routine analysis of drugs in commercial tablets. Hence, it could be used in the analysis of laboratory samples and marketed formulations containing these two drugs in combined dosage form without the interference of common excipients.

Keywords: Simultaneous equation method, Q-absorbance ratio method, Salbutamol, Doxophylline

(C) 2017 The Authors. Published by Innovare Academic Sciences Pvt Ltd. This is an open access article under the CC BY license (http://creativecommons.org/licenses/by/4.0/) DOI: http://dx.doi.org/10.22159/ijpps.2017v9i6.14938

\section{INTRODUCTION}

SBS is chemically (RS)-2-(hydroxymethyl)-4-\{1-hydroxy-2-[(2-methyl-2propanyl)-amino] ethyl $\}$ phenol sulfate (2:1) (fig. 1). It is $\beta 2$-adrenergic receptor agonist used for the relief of bronchospasm in conditions such as asthma and chronic obstructive pulmonary disease. Selective $\beta 2$ adrenoceptor stimulant that causes the relaxation of the smooth muscles through the increase of the intracellular cyclic adenosine monophosphate (cAMP) due to this, bronchial and uterine muscles get relaxed, the peripheral vessels are dilated and heart rate increases. Activation of the $\beta-2$ adrenoreceptors opens ATPase channels and drives potassium from the extra cellular to the intracellular space. This both decreases extracellular hyperkalaemia and increases intracellular potassium, so decreasing the chance of arrhythmia [1-3].

DOX is chemically 7(1,3 dioxolone-2-yl-methyl)-1,3-dimethylpurine-2,6dione (fig. 2). It is bronchodilator xanthine drug which has the therapeutic properties of theophylline with lower incidence of sideeffects [4]. Doxophylline do not affect gastric acid secretion; either in vivo or in vitro; unlike theophylline. The lack of side effects with DOX indicates that the drug can be used safely and effectively in the treatment of COLD. DOX inhibits phosphodiesterase (PDE IV) activities with consequent increase of cyclic AMP that determines relaxation of smooth musculature. DOX appears to have decreased affinities toward adenosine $\mathrm{A} 1$ and $\mathrm{A} 2$ receptors which may account for the better safety profile of the drug. DOX does not interfere with calcium influx into the cells or antagonize calcium channel blockers. Unlike aminophylline it has low secretagogue activity and suitable for asthmatic patients with peptic ulcer disease. DOX is used in the treatment of bronchial asthma, chronic obstructive pulmonary disease (COPD) and chronic bronchitis [5-6].

SBS is official in European Pharmacopoeia [7], which describes a potentiometric titration in non-aqueous medium. SBS alone or in combination with other drugs is reported to be estimated by HPLC in pharmaceutical dosage form [8-11], plasma; titrimetric [12], TLC, microtitrimetric, conductometric, HPLC, UV-spectrophotometry and immunoaffinity-chromatography. Some analytical methods for quantitative determination of doxophylline in pharmaceutical formulations are described in literature are some of reported methods used for analysis. UV-spectrophotometry estimation of doxophylline in biological samples, plasma and serum [13-19].

Extensive literature survey has revealed that no UV spectroscopic method is reported for simultaneous determination of SBS and DOX in combine dosage form. The UV spectrophotometric analysis is often preferred in quality control testing and ordinary laboratories due to its broader availability, suitability and ease of use. Therefore, in the present work successful attempt has been made to estimate both the drugs simultaneously by two simple UV spectrophotometric methods i. e simultaneous equation method and Q-absorbance ratio method in combine dosage form. The proposed methods were optimized and validated as per ICH guidelines [20-26].

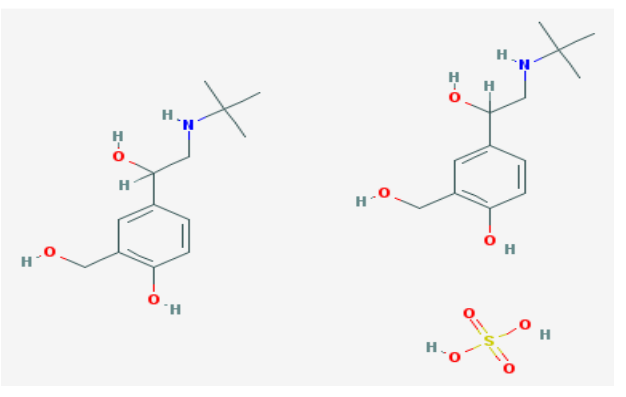

Fig. 1: Structure of SBS [27] 


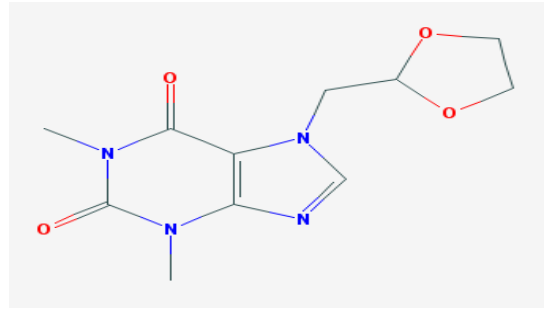

Fig. 2: Structure of DOX [28]

\section{MATERIALS AND METHODS}

\section{Instruments}

Absorbance measurements were made on double beam UV-Visible spectrophotometer, model 1800, Shimadzu, Japan, with software UV Probe 2.10 and $1 \mathrm{~cm}$ matched quartz cells

\section{Chemicals}

Gift samples of salbutamol sulphate and doxophylline were provided by Key Pharmaceuticals Limited, Ambala, Haryana, India. The pharmaceutical dosage form used in the study was Doxoril plus 4 (Macleods Pharmaceuticals Pvt Ltd). Each uncoated tablet contains 4 mg SBS and $400 \mathrm{mg}$ DOX. All chemicals were of analytical reagent grade and solutions were prepared with double distilled water.

\section{Preparation of standard stock solution}

Standard stock solutions $(20 \mu \mathrm{g} / \mathrm{ml})$ of both of SBS and DOX were prepared separately by dissolving accurately weighed $(2.0 \mathrm{mg})$ quantity of pure SBS and DOX in $100 \mathrm{ml}$ volumetric flask and diluting up to the mark with phosphate buffer ( $\mathrm{pH}$ 7.4) to get working standard solution of each containing $20 \mu \mathrm{g} / \mathrm{ml}$ of both SBS and DOX.

\section{Preparation of working standard solutions}

From the above stock solution desired concentrations were prepared by transferring specific volume to separate $10 \mathrm{ml}$ volumetric flasks and volume was made up to $10 \mathrm{ml}$ with phosphate buffer.

\section{Determination of isoabsorptive point and absorption maxima}

By appropriate dilution of standard solutions of SBS and DOX with phosphate buffer ( $\mathrm{pH}$ 7.4), solutions containing $10 \mu \mathrm{g} / \mathrm{ml}$ of both drugs were scanned separately in the range of $200-400 \mathrm{~nm}$ against phosphate buffer ( $\mathrm{pH}$ 7.4) as blank. The overlaying spectrum was also obtained to determine isoabsorptive point and wavelength of maximum absorbance $\lambda$ max of both the drugs.

\section{Methods}

\section{Simultaneous equation method (Method A)}

$1 \mu \mathrm{g} / \mathrm{ml}$ solutions of SBS and DOX were prepared separately in phosphate buffer ( $\mathrm{pH}$ 7.4) and the solutions were scanned against blank in the entire UV range to determine the $\lambda$ max values. Clear peaks were observed at $272 \mathrm{~nm}$ for SBS and $276 \mathrm{~nm}$ for DOX. Hence these wavelengths were chosen as $\lambda$ max values for each drug respectively (fig. 1). Standard solutions of SBS and DOX in the concentration range 0.1$5 \mu \mathrm{g} / \mathrm{ml}$ were prepared in the phosphate buffer $(\mathrm{pH} 7.4)$ and the absorbance of these solutions was measured at $272 \mathrm{~nm}$ and $276 \mathrm{~nm}$. Calibration curves were plotted to verify the Beer's law and the absorptivity values calculated at the respective wavelengths for both the drugs. Two simultaneous equations as below were formed using these absorptivity values $\mathrm{A}(1 \%, 1 \mathrm{~cm})[21-24]$

$$
\begin{aligned}
& \text { At } \lambda_{1} A_{1}=a_{1} b_{1}+a y_{1} b C_{y} \ldots . .(1) \\
& \text { At } \lambda_{2} A_{2}=a_{2} b_{x}+a_{2} b_{y} \ldots \ldots . .(2)
\end{aligned}
$$

For measurements in $1 \mathrm{~cm}$ cells $\mathrm{b}=1$

Rearrange eq. (2)

$$
\mathrm{Cy}=\frac{\mathrm{A} 2-\mathrm{ax} 2 \mathrm{Cx}}{\mathrm{ay} 2}
$$

Substituting for Cy in eq (1) and rearranging

$$
\begin{aligned}
& \mathrm{Cx}=\frac{\mathrm{A} 2 \mathrm{ay} 1-\mathrm{A} 1 \mathrm{ay} 2}{\mathrm{ax} 2 \mathrm{ay} 1-\mathrm{ax} 1 \mathrm{ay} 2} \ldots \ldots . . . .(3) \\
& \mathrm{Cy}=\frac{\mathrm{A} 1 \mathrm{ax} 2-\mathrm{A} 2 \mathrm{ax} 1}{\mathrm{ax} 2 \mathrm{ay} 1-\mathrm{ax} 1 \mathrm{ay} 2} \ldots \ldots \ldots . . .(4)
\end{aligned}
$$

Where, $\mathrm{Cx}$ and $\mathrm{Cy}$ are the concentrations of SBS and DOX measured in $\mathrm{gm} / 100 \mathrm{ml}$ in sample solutions, A1 and A2 are absorbance of mixture at selected wavelengths $272 \mathrm{~nm}$ and $276 \mathrm{~nm}$ respectively.

\section{Absorbance ratio method/Q-analysis (method B)}

The absorbance ratio method is a modification of the simultaneous equation procedure. It depends on the property that for a substance, which obey Beer's law at all wavelength, the ratio of absorbance at any two wavelengths in constant value independent of concentration or path length. E. g. two dilutions of the same substance give the same absorbance ratio A1/A2. In the USP, this ratio is referred to as $Q$ value. In the quantitative assay of two components in admixture by the absorbance ratio method, absorbance are measured at two wavelengths, one being the $\lambda_{\max }$ of one of the component $\left(\lambda_{2}\right)$ and the other being wavelength of equal absorptivity of two components $\left(\lambda_{1}\right)$ i.e. an isoabsorptive point.

A series of standard solutions of SBS and DOX in the concentration range of $0.1-5 \mu \mathrm{g} / \mathrm{ml}$ were prepared in phosphate buffer and the absorbance of these solutions was measured at $225 \mathrm{~nm}$ (isoabsorptive point) and $276 \mathrm{~nm}$ ( $\lambda_{\max }$ of DOX) (fig. 1). Calibration curves were plotted to verify the Beer's law and the absorptivity values calculated at the respective wavelength for both the drugs. The absorptivity values were reported in table 1. [21-24]

The concentration of two drugs in mixture was calculated by using the following equations:

$$
\begin{aligned}
& \mathbf{C} \mathbf{x}=\frac{Q m-Q y}{Q x-Q y} \times \frac{A \mathbf{1}}{a x \mathbf{1}} . \\
& \mathbf{C y}=\frac{Q m-Q x}{Q y-Q x} \times \frac{\mathbf{A 1}}{a y \mathbf{1}} .
\end{aligned}
$$

Where $\mathrm{Qm}=\mathrm{A}_{2} / \mathrm{A}_{1}, \mathrm{Qx}=\mathrm{ax}_{2} / \mathrm{ax}_{1}, \mathrm{Qy}=\mathrm{ay}_{2} / \mathrm{ay}_{1}$

$A_{1}$ is absorbance of mixture at isosbestic point i. e $225 \mathrm{~nm}$

$\mathrm{A}_{2}$ is absorbance of mixture at $276 \mathrm{~nm} \lambda_{\max }$ of DOX

$\mathrm{ax}_{1}$ and $\mathrm{ax}_{2}$ represent absorptivities of SBS at $225 \mathrm{~nm}$ and $276 \mathrm{~nm}$

ay $_{1}$ and ay $_{2}$ denotes absorptivities of DOX at $225 \mathrm{~nm}$ and $276 \mathrm{~nm}$.

Cx and Cy are the concentration of SBS and DOX.

\section{Validation of proposed method (Method A and B)}

The method was validated according to ICH guidelines for validation of analytical procedures in order to determine linearity, sensitivity, accuracy and precision for each analyte [20].

\section{Linearity}

Appropriate dilutions of working standard solutions for SBS and DOX were prepared in the concentration range of $0.1-5 \mu \mathrm{g} / \mathrm{ml}$ and $0.1-3 \mu \mathrm{g} / \mathrm{ml}$, respectively and analyzed as per the developed methods $\mathrm{A}$ and B. Calibration curves were generated and the linearity was evaluated by the least square regression method. The results are reported in table 1,5 .

\section{Accuracy (Recovery studies)}

To ascertain the accuracy of the proposed methods, recovery studies were carried out by standard addition method at three different levels according to ICH guidelines. A series of solutions of SBS and DOX at $80 \%, 100 \%$, and $120 \%$ of the standard preparation in the ratio of the formulation were prepared and checked for accuracy by determining the absorbance values at $\lambda_{\max }$ of $272 \mathrm{~nm}$ and $276 \mathrm{~nm}$ (Method A) and $225 \mathrm{~nm}$ and $276 \mathrm{~nm}$ (method B) respectively. To a fixed concentration of the formulation, varying concentrations of pure drug solutions were added and percentage recoveries calculated. The result of the analysis is given in table 2,3 . 


\section{Precision}

Precision is the degree of repeatability of analytical method under normal operational conditions. The precision of the assay was determined by repeatability (intraday) and intermediate (interday) and reported as \%RSD for a statistically significant number of replicate measurement. The intermediate precision was studied by comparing the assays on three different days and the results documented as standard deviation and \%RSD.

Precision studies were performed in triplicate at three different concentration levels covering the entire linearity range for SBS and DOX. The result of the analysis is given in table 4 .

\section{Limit of detection (LOD) and limit of quantification (LOQ)}

The detection limit of an individual analytical procedure is the lowest amount of analyte in the sample which can be detected but not necessarily quntitated as an exact value. The quantitation limit of an individual analytical procedure is the lowest amount of analyte in the sample which can be quantitatively determined with suitable precision and accuracy. The LOD and LOQ of the proposed method were determined by using calibration curve: (table 5)

$$
\begin{aligned}
& \text { LOD }=\frac{3.3 \sigma}{\mathrm{s}} \\
& \mathrm{LOQ}=\frac{10 \sigma}{\mathrm{s}}
\end{aligned}
$$

Where, $\sigma$ is mean standard deviation of y-intercepts of regression lines, $\mathrm{s}$ is slope of the standard curve.

\section{Assay of tablets formulation}

For estimation of drugs in the commercial formulations, twenty tablets containing $400 \mathrm{mg}$ DOX and $4 \mathrm{mg}$ of SBS were weighed and average weight was calculated. The tablets were crushed and powdered in glass mortar. For the analysis of drugs, quantity of powder equivalent to $1 \mathrm{mg}$ of SBS and100 mg of DOX was transferred to $100 \mathrm{ml}$ volumetric flask and dissolved in sufficient quantity of phosphate buffer. It was sonicated for $30 \mathrm{~min}$ and volume was made upto obtain a stock solution $10 \mu \mathrm{g} / \mathrm{ml}$ of SBS and $1000 \mu \mathrm{g} / \mathrm{ml}$ of DOX. This solution was then filtered through watmann filter paper \#42. Further dilutions were made from this stock solution to get required concentration. In method $A$, the concentration of SBS and DOX was determined by measuring absorbance of sample solutions at $272 \mathrm{~nm}\left(\lambda_{\max }\right.$ of SBS) and276 nm ( $\lambda_{\max }$ of DOX) using simultaneous equation. In method B, the concentration of both SBS and DOX was determined by measuring absorbance of sample solutions at $276 \mathrm{~nm}\left(\lambda_{\max }\right.$ of DOX; $\left.\lambda_{2}\right)$ and 225 $\mathrm{nm}$ (isosbestic point of both drugs; $\lambda_{1}$ ). The results of analysis and statistical validation for the marketed tablet formulation are reported in table 2-4. The results of recovery studies conducted by the addition of different amount of pure drugs at different levels to a tablet solution were found to be satisfactory.

\section{RESULTS AND DISCUSSION}

The simultaneous equation method is generally used to estimate two absorbing substances (SBS and DOX) each of which absorbs at the wavelength of the other drug. By constructing and placing values in simultaneous equations 3 and 4 the concentration of two drugs was determined. The absorption ratio method generally used to estimate two absorbing substances (SBS and DOX) each of which absorbs at the wavelength of the other by constructing and placing values in absorption ratio equation 5 and 6 to determine the concentration of SBS and DOX.

SBS and DOX exhibited maximum absorption at $272 \mathrm{~nm}$ and $276 \mathrm{~nm}$ (Method A), so using these wavelengths simultaneous equation method for analysis of SBS and DOX in combine form was developed. For Q-absorption method (Method B) of simultaneous analysis of SBS and DOX in combine form, $225 \mathrm{~nm}$ (iso-absorptive point) and $276 \mathrm{~nm}$ ( $\lambda_{\max }$ of DOX) was used. Beer's law were found to be obeyed in the concentration range between $0.2-1.6 \mu \mathrm{g} / \mathrm{ml}$ and 0.1 to $3.5 \mu \mathrm{g} / \mathrm{ml}$ at 276 $\mathrm{nm} ; 0.2-1.6 \mu \mathrm{g} / \mathrm{ml}$ and $0.1-4.5 \mu \mathrm{g} / \mathrm{ml}$ at $272 \mathrm{~nm}$ and 0.2 to $2.0 \mu \mathrm{g} / \mathrm{ml}$ and 0.2 to $3.5 \mu \mathrm{g} / \mathrm{ml}$ at iso-absorptive point $225 \mathrm{~nm}$ for SBS and DOX respectively (Method A and B). Calibration curves were prepared for both the drugs at $276 \mathrm{~nm}, 272 \mathrm{~nm}$ and $225 \mathrm{~nm}$ (fig. 4-6, table 1, 5). The overlain UV-absorption spectra of SBS $(272 \mathrm{~nm})$ and DOX $(276 \mathrm{~nm})$ showed isoabsorptive point $(225 \mathrm{~nm})$ in ethanol is shown in fig. 3. All calibration curve obtained was linear with coorelation coefficient $\left(\mathrm{r}^{2}\right)$ greater than 0.998 . Hence the relationship between the concentrations and absorbances of SBS and DOX showed linearity (table 5).

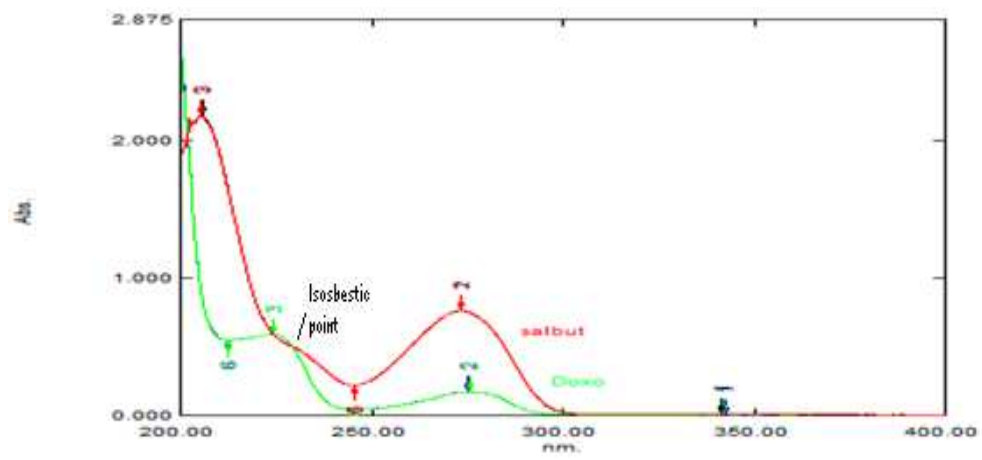

Fig. 3: UV overlay spectrum of SBS and DOX showing isoabsorptive point

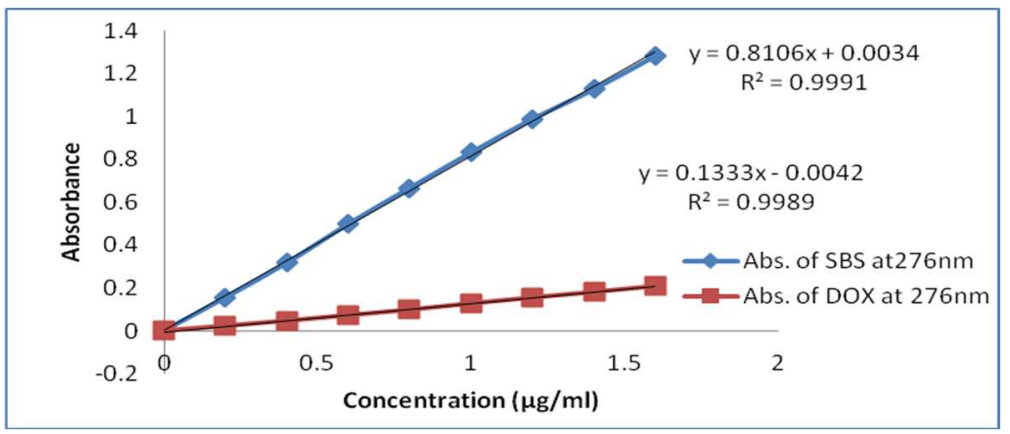

Fig. 4: Calibration curve of SBS and DOX at $276 \mathrm{~nm}$ 


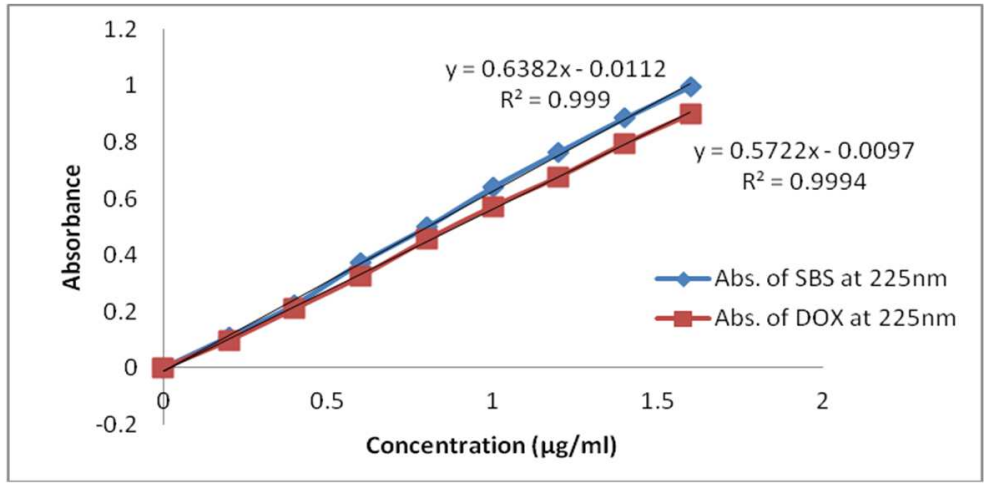

Fig. 5: Calibration curve of SBS and DOX at $225 \mathrm{~nm}$

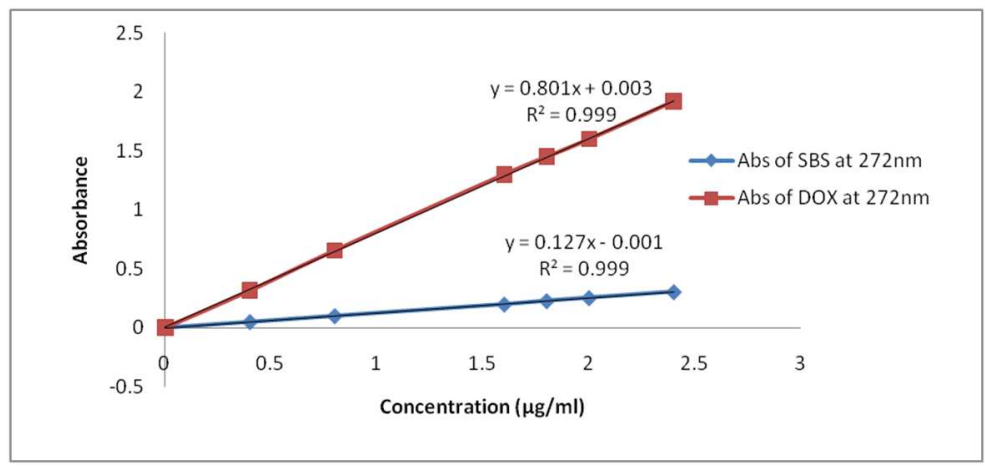

Fig. 6: Calibration curve of SBS and DOX at $272 \mathrm{~nm}$

Table 1: Absorptivity values (A1\%, $1 \mathrm{~cm})$ of SBS and DOX for methods $A$ and B i. e at all three $(225 \mathrm{~nm}, 276 \mathrm{~nm}$ and $272 \mathrm{~nm})$ wavelengths

\begin{tabular}{|c|c|c|c|c|c|c|}
\hline \multirow[t]{3}{*}{ Concentration of the solution $(\mu \mathrm{g} / \mathrm{ml})$} & \multicolumn{6}{|c|}{ Absorptivity, A(1\%, $1 \mathrm{~cm})$} \\
\hline & \multicolumn{3}{|c|}{ SBS mean absorptivity $(n=3)$} & \multicolumn{3}{|c|}{ DoX mean absorptivity $(n=3)$} \\
\hline & $225 \mathrm{~nm}$ & $276 \mathrm{~nm}$ & $272 \mathrm{~nm}$ & $225 \mathrm{~nm}$ & $276 \mathrm{~nm}$ & $272 \mathrm{~nm}$ \\
\hline 0.4 & 6400 & 7925 & 7900 & 5625 & 1175 & 1225 \\
\hline 0.6 & 6200 & 8300 & 8200 & 5750 & 1216 & 1250 \\
\hline 0.8 & 6237 & 8325 & 8000 & 5637 & 1237 & 1265 \\
\hline 1 & 6400 & 8320 & 7444 & 5600 & 1210 & 1261.9 \\
\hline 1.2 & 6375 & 8233 & 8175 & 5666 & 1216 & 1270 \\
\hline 1.4 & 6321 & 8057 & 8007 & 5678 & 1214 & 1243.75 \\
\hline 1.6 & 6231 & 8018 & 7500 & 5618 & 1231 & 1268 \\
\hline Mean & 6309.311 & 8116.153 & 7889.429 & 5665.811 & 1225.171 & 1254.809 \\
\hline
\end{tabular}

Each value represents mean value $(n=3)$

The validation parameters were studied on marketed formulation at all the wavelengths for the proposed methods. As per IP, tablets should contain not less than $95.0 \%$ and not more than $105.0 \%$ of active ingredients of the stated amount. The average \% drug content was found to be of $97-98 \%$ and $96.89-98.16 \%$ for SBS and DOX by Method A and Method B respectively, which was found to be within the acceptance limit with \%RSD values less than the limit of $2 \%$. Accuracy was determined by calculating the recovery by standard addition method. Results revealed percentage recovery more than 97.50\% with \% RSD value within the accepted limit for both the components by both methods at all the three levels of recovery analysis. Hence both the proposed methods were found to be accurate for estimation of SBS and DOX in tablet formulation. Both the methods were subjected for study of repeatability, intraday and interday precision for both the drugs. \% RSD values for repeatability, intraday and interday precision were calculated and found to be well below the specified limit of $2 \%(\% \mathrm{RSD}<2)$ indicating good precision in the specified range (table 4). The sensitivity of the proposed methods was determined in terms of limit of detection (LOD) and limit of quantitation (LOQ). LOD values for SBS and DOX were found to be 0.048 and $0.064 \mu \mathrm{g} / \mathrm{ml}$ at $276 \mathrm{~nm} ; 0.048$ and 0.013 at $272 \mathrm{~nm}$ and 0.015 and $0.057 \mu \mathrm{g} / \mathrm{ml}$ at $225 \mathrm{~nm}$. LOQ values for SBS and DOX were found to be 0.148 and $0.195 \mu \mathrm{g} / \mathrm{ml}$ at $276 \mathrm{~nm} ; 0.158$ and $0.042 \mu \mathrm{g} / \mathrm{ml}$ at $272 \mathrm{~nm}$ and 0.047 and $0.173 \mu \mathrm{g} / \mathrm{ml}$ at $225 \mathrm{~nm}$. (table 5)

Table 2: Statistical parameters for marketed formulation: Doxoril plus 4 (SBS and DOX) by methods A and B

\begin{tabular}{lllll}
\hline S. No. & Drug & Label claim (mg) & Amount found & \% Recovery \\
\hline Method A & SBS & 4 & 3.92 & 98 \\
& DOX & 400 & 392.65 & 98.162 \\
Method B & SBS & 4 & 3.88 & 97 \\
& DOX & 400 & 378.56 & 0.012 \\
\hline
\end{tabular}

Each value is given in mean+\% RSD 
Table 3: Recovery studies on marketed formulations of SBS and DOX by methods A and B

\begin{tabular}{llll}
\hline Recovery Level \% & \multicolumn{2}{l}{ \% recovery (mean \pm S. D) } & Method B \\
\cline { 2 - 4 } & Method A & DOX & SBS \\
\cline { 2 - 4 } & SBS & $98.36 \pm 1.223$ & $98.05 \pm 0.121$ \\
\hline 80 & $98.39 \pm 1.113$ & $98.59 \pm 1.412$ & $97.49 \pm 0.610$ \\
100 & $97.45 \pm 0.916$ & $97.82 \pm 1.524$ & $98.87 \pm 0.912$ \\
Mean & $98.63 \pm 1.018$ & $98.257 \pm 1.386$ & $97.976 \pm 0.547$ \\
\hline
\end{tabular}

Each value represents mean $\pm \operatorname{SD}(n=3)$

Table 4: Validation parameters analysis of SBS and DOX by methods A and B

\begin{tabular}{|c|c|c|c|c|c|c|c|c|}
\hline Parameter & Method A & & & & Method B & & & \\
\hline Precision (mean \pm SD) & SBS & \%RSD & DOX & \%RSD & SBS & \%RSD & DOX & \%RSD \\
\hline Repeatability & $98.12 \pm 1.09$ & 1.113 & $97.36 \pm 0.69$ & 0.934 & $98.02 \pm 1.21$ & 1.052 & $98.62 \pm 0.94$ & 0.953 \\
\hline Day to Day & $98.35 \pm 0.85$ & 0.864 & $98.09 \pm 1.53$ & 0.654 & $98.01 \pm 1.08$ & 0.618 & $98.43 \pm 0.88$ & 0.804 \\
\hline Analyst to Analyst & $97.63 \pm 0.94$ & 0.954 & $98.56 \pm 1.05$ & 1.140 & $98.24 \pm 0.81$ & 0.466 & $99.25 \pm 0.67$ & 1.04 \\
\hline Reproducibility & $97.62 \pm 1.08$ & 1.046 & $97.06 \pm 0.85$ & 1.039 & $97.06 \pm 1.06$ & 0.647 & $97.86 \pm 0.76$ & 0.982 \\
\hline
\end{tabular}

Each value represents mean \pm SD $(n=3)$

Table 5: Regression analysis data

\begin{tabular}{|c|c|c|c|c|c|c|}
\hline \multirow[t]{2}{*}{ Parameters } & \multicolumn{2}{|l|}{$276 \mathrm{~nm}$} & \multicolumn{2}{|l|}{$225 \mathrm{~nm}$} & \multicolumn{2}{|l|}{$272 \mathrm{~nm}$} \\
\hline & SBS & DOX & SBS & DOX & SBS & DOX \\
\hline Linearity $(\mu \mathrm{g} / \mathrm{ml})$ & $0.2-1.6$ & $0.2-3.5$ & $0.2-2.0$ & $0.2-3.5$ & $0.2-1.6$ & $0.1-4.5$ \\
\hline $\begin{array}{l}\text { Molar Absorptivity } \\
\left(1 \mathrm{~mol}^{-1} \mathrm{~cm}^{-1}\right)\end{array}$ & 194459 & 32615 & 150785 & 15068 & 188547 & 33356 \\
\hline $\begin{array}{l}\text { Regression Equation } \\
(y=m x+c)\end{array}$ & $Y=0.810 x+0.003$ & $Y=0.133 x-0.004$ & $Y=0.638 x-0.011$ & $Y=0.572 x-0.009$ & $Y=0.801 x+0.03$ & $Y=0.127 x-0.001$ \\
\hline Slope (m) & 0.810 & 0.133 & 0.638 & 0.572 & 0.801 & .127 \\
\hline Intercept (c) & 0.003 & -0.004 & -0.011 & -0.009 & 0.03 & 0.001 \\
\hline Correlation coefficient $\left(\mathrm{r}^{2}\right)$ & 0.998 & 0.999 & 0.998 & 0.999 & 0.999 & 0.999 \\
\hline $\mathrm{LOD}(\mu \mathrm{g} / \mathrm{ml})$ & 0.048 & 0.064 & 0.015 & 0.057 & 0.048 & 0.013 \\
\hline $\mathrm{LOQ}(\mu \mathrm{g} / \mathrm{ml})$ & 0.148 & 0.195 & 0.047 & 0.173 & 0.158 & 0.042 \\
\hline
\end{tabular}

Therefore the result shows that both the proposed methods are specific, accurate and precise as indicated by good recovery results and within acceptance limit relative standard deviation (RSD) values for simultaneous quantitation of SBS and DOX in bulk drug and combined dosage form. Overall proposed methods were found to be suitable for simultaneous quantitative estimation of both the drugs in pharmaceutical dosage form.

\section{CONCLUSION}

Two new, simple, sensitive and economical UV spectrophotometric methods were developed for the simultaneous analysis of SBS and DOX in bulk and in pharmaceutical formulations. The developed methods were validated and from the statistical data, it was found that the methods were linear, accurate and precise and can be successfully applied for the analysis of pharmaceutical formulations without interference of excipients.

The UV spectrophotometric simultaneous equation method and $Q$ absorption ratio method was developed and validated for the simultaneous analysis of SBS and DOX. The results together established that the methods are simple, accurate, precise, reproducible, rapid, and sensitive. The method could be applied successfully and economically for the simultaneous estimation of SBS and DOX in laboratory samples for efficient data generation and for combination formulations of these two drugs in the future.

\section{CONFLICT OF INTERESTS}

\section{Declared none}

\section{REFERENCES}

1. Barnes PJ, Page CP. Pharmacology and therapeutics of asthma and COPD. Springer-Verlag Berlin Heidelberg, Germany; 2004. p. 15.
2. Robert AS. Chronic obstructive pulmonary disease, Blackwell Publishing House, UK; 2007. p. 680.

3. Brum PC, Rolim NPL, Bacurau AVN, Medeiros A. Rhizophores in rhizophora mangle L: an alternative interpretation of so-called “aerial roots. Ann Brazilian Acad Sci 2006;78:485-503.

4. Villani F, De Maria P, Ronchi E, Galimberti M. Oral doxofylline in patients with chronic obstructive pulmonary disease. Int J Clin Pharmacol Ther 1997;35:107-11.

5. Cirillo R, Barone D, Franzone JS. Doxofylline, an antiasthmatic drug lacking affinity for adenosine receptors. Arch Int Pharmacodyn Ther 1988;295:221-37.

6. Dini FL, Cogo R. Doxofylline: a new generation xanthine bronchodilator devoid of major cardiovascular adverse effects. J Curr Med Res Opin 2001;16:258-68.

7. European Pharmacopoeia. EDQM, Strasbourg; 2005. p. 3611.

8. The British Pharmacopoea. Her Majesty's Stationery Office, London; 1998. p. 1151-2.

9. Indian Pharmacopoeia. The Controller of Publications, Ministry of Health and Family Welfare, Government of India, New Delhi; 1996. p. 670-3.

10. Bernal TL, del-Nozal MJ, Velasco H, Toribio L. HPLC versus SFC for the determination of salbutamol sulphate and its impurities in pharmaceuticals. J Liq Chromatogr Rel Technol 1996;19:1579-89.

11. Ray S, Bandopadhyay A. Reversed phase high performance liquid chromatographic determination of salbutamol sulphate in pharmaceutical formulations. Indian Drugs 1990;27:313-6.

12. Talwar N, Singhai AK, Shakya AK, Saraf S, Jain NK. Difference spectrophotometric determination of salbutamol sulphate in tablets. Indian Drugs 1991;28:244-5.

13. Habib IHI, Hassouna MEM, Zaki GA. Simultaneous spectrophotometric determination of salbutamol and bromhexin in tablets. Farmaco 2005;60:249-54. 
14. Reddy MN, Sankar DG, Rao GD, Sreedhar K. Spectrophotometric determination of salbutamol and terbutaline. East Pharm 1991;34:127-8.

15. Basu M, Pathak B. Estimation of salbutamol sulphate in pharmaceutical formulations. Indian Drugs 1990;28:109-10.

16. Geetha N, Baggi TR. Improved spectrophotometric method for the determination of salbutamol sulphate with 3-methyl benzothiazolin-2-one hydrazone. Microchem J 1989;39:137-44.

17. Naidu NV, Naidu DV, Rajeshwari CV, Naidu PR. Simple spectrophotometric determination of salbutamol sulphate in pharmaceutical formulations. Acta Chim Hung 1989;126:821-4.

18. Vishwanth KK, Rao AS, Shivaramakrishnan MV. Colorimetric determination of salbutamol in pharmaceutical preparations. Indian Drugs 1989;26:516-8.

19. Patel RB, Patel AS, Pallavi U. Spectrophotometric determination of salbutamol sulphate and its combination in pharmaceutical dosage forms. Indian Drugs 1987;24:298-302.

20. ICH-International Conference on Harmonization. Topic Q2B, Validation of Analytical Methods: Methodology. The Third International Conference on Harmonization of Technical Requirements for Registration of Pharmaceuticals for Human Use Yokohama-Japan; 2005;8:71-6.

21. Beckett AH, Stenlake JB. Practical Pharmaceutical Chemistry. $4^{\text {th }}$ ed. part one, published by CBS Publishers and Distributors, New Delhi, India; 2005. p. 133-6.

22. Beckett AH, Stenlake JB. Practical Pharmaceutical Chemistry. $4^{\text {th }}$ ed. part two, published by CBS Publishers and Distributors, New Delhi, India; 2005. p. 275-306.
23. Mendham J, Denney RC, Barnes JD, Thomas MJK. Vogel's Quantitative Chemical Analysis. 6 ${ }^{\text {th }}$ ed. Published by pearson Education, Delhi, India; 2004. p. 630-6.

24. Kamboj A, Matta Y, Kohar V. Development and validation of ultra violet spectrophotometric method for determination of acid dissociation constant of tramadol hydrochloride. W J Pharm Res 2016;5:582-99.

25. Patel PA, Dole MN, Shedpure PS, Sawant SD. Spectrophotometric simultaneous estimation of salbutamol and ambroxol in bulk and formulation. Asian J Pharm Clin Res 2011;4:42-5.

26. Kant R, Bodia R, Kapoor G, Bhutani R. Development and validation of novel spectrophotometric methods for simultaneous estimation of pioglitazon and metformin in bulk and fixed dosage forms by area under curve and dual wavelength mode. Inter J Appl Pharm 2016;8:48-53.

27. https://pubchem.ncbi.nlm.nih.gov/image/fl.html?cid=39859. [Last accessed on 10 Jul 2016]

28. https://pubchem.ncbi.nlm.nih.gov/image/fl.html?cid=50942. [Last accessed on 10 Jul 2016]

\section{How to cite this article}

- Anjoo Kamboj, Pawan Sidana, Upendra K Jain. Development and validation of UV spectroscopic methods for simultaneous estimation of salbutamol sulphate and doxophylline in combined solid dosage form. Int J Pharm Pharm Sci 2017;9(6):117-122. 